\title{
The blood pressure response to vasodilator stress does not provide independent prognostic information
}

\author{
Eliana Reyes, MD, PhD, FESC, ${ }^{\mathrm{a}}$ and Fadi G. Hage, MD, FASH, FACC, FASNC ${ }^{\mathrm{b}, \mathrm{c}}$ \\ ${ }^{a}$ Royal Brompton and Harefield Hospitals, London, UK \\ ${ }^{b}$ Division of Cardiovascular Disease, Department of Medicine, The University of Alabama at \\ Birmingham, Birmingham, AL \\ c Section of Cardiology, Birmingham Veterans Affairs Medical Center, Birmingham, AL
}

Received Aug 10, 2016; accepted Aug 10, 2016

doi:10.1007/s12350-016-0651-8

\section{See related article, pp. 1966-1975}

Vasodilator myocardial perfusion imaging (MPI) provides a large wealth of prognostic data that are related to the perfusion pattern ${ }^{1-4}$ and to a vast array of nonperfusion variables as recently reviewed in the Journal. ${ }^{5}$ This prognostic data are important for risk stratification and can help guide clinical management of patients. The use of nonperfusion variables to augment the prognostic data provided by MPI is especially important when vasodilator stress is used in lieu of exercise, since patients referred for vasodilator MPI are at higher risk than those referred for exercise MPI, irrespective of the perfusion pattern, ${ }^{6}$ and since functional capacity, a very strong prognostic index, ${ }^{7}$ cannot be assessed when using vasodilators. In this issue of the Journal, Witbrodt et $\mathrm{al}^{8}$ evaluate the prognostic value of the blood pressure (BP) response to vasodilator stress using data from the positron emission tomography (PET) Prognosis registry.

\section{BLOOD PRESSURE RESPONSE TO EXERCISE}

The BP response to dynamic exercise has long been recognized as an essential parameter that enhances the interpretation of the exercise ECG. ${ }^{9}$ The normal response

Reprint requests: Fadi Hage, MD, FASH, FACC, FASNC, Division of Cardiovascular Disease, Department of Medicine, The University of Alabama at Birmingham, Lyons Harrison Research Building 306, 1900 University BLVD, Birmingham AL 35294; fadihage@uab.edu J Nucl Cardiol 2017;24:1976-8.

$1071-3581 / \$ 34.00$

Copyright (c) 2016 American Society of Nuclear Cardiology. to incremental exercise consists of a progressive rise in systolic BP and a small decrease or no change in diastolic $\mathrm{BP}$, resulting in a modest increase in mean $\mathrm{BP}$ and a widening of the pulse pressure. ${ }^{10}$ This response reflects the progressive increase in cardiac output and the accompanying decrease in peripheral vascular resistance that occur in order to meet the increasing demand of oxygen by the exercising muscle. This normal increase in BP parallels the intensity of the exercise performed and reaches its peak value at maximal or near-maximal exercise capacity. ${ }^{9}$ At this point, peak systolic BP should not exceed $230 \mathrm{~mm}$ Hg. ${ }^{11}$ A disproportionate or excessive rise in BP is associated with an increased likelihood of developing hypertension and a higher risk of cardiac death among subjects without overt heart disease. ${ }^{12}$ In patients with known or suspected heart disease, an increase in BP, even if above the upper limit of normal range, is associated with better prognosis compared to that of a hypotensive or no response to dynamic exercise. ${ }^{13}$ Indeed, a reduction in systolic BP during exercise is a marker of heart disease, and, in patients with coronary artery disease (CAD), in particular, this response has both diagnostic and prognostic implications.

Exercise-induced hypotension is commonly defined as a decrease in systolic BP during exercise below its resting or pre-test value. ${ }^{9}$ Other definitions include failure to increase by more than $10 \mathrm{~mm} \mathrm{Hg}$ from baseline or a decrease of more than $20 \mathrm{~mm} \mathrm{Hg}$ after an initial rise. A hypotensive response to exercise is considered a marker of ischemia-induced left ventricular dysfunction in patients with obstructive CAD. ${ }^{9}$ It is also associated with a higher risk of complications during the exercise test. ${ }^{9}$ In the presence of clinical, electrocardiographic, and imaging findings of myocardial ischemia, an abnormally low systolic BP response to exercise is associated with significant CAD including three-vessel and left main stem 
diseases. ${ }^{14}$ It is generally accepted that a reduction in systolic BP during exercise is an independent predictor of worse outcome. ${ }^{9,10}$ In a recent large study of more than 44 thousand patients referred for exercise stress testing (mean age $53 \pm 13$ years, $45 \%$ female, $26 \%$ black, $22 \%$ obese) who were followed up for a median of 10 years, a decreased systolic BP response was associated with worse outcomes even after adjusting for demographics, physical fitness, and cardiovascular risk factors. ${ }^{15}$ Compared to patients who experienced a rise in BP of more than $20 \mathrm{~mm} \mathrm{Hg}$ from baseline, even a modest attenuation of the BP response ( 1 to $20 \mathrm{~mm} \mathrm{Hg}$ rise from baseline) was associated with a $13 \%$ increase in mortality (hazard ratio $1.13,95 \%$ CI 1.05-1.22), while an exercise-induced drop in BP was associated with a $21 \%$ increase in mortality $(1.21,1.09-1.34)$.

\section{BLOOD PRESSURE RESPONSE TO VASODILATOR STRESS}

In contrast to exercise, where BP normally rises during the test, $\mathrm{BP}$ is expected to decrease during vasodilator stress. For example, in the ADenosine Versus RegAdenosoN Comparative Evaluation for Myocardial Perfusion Imaging (ADVANCE MPI) trial, systolic BP decreased by $14 \pm 13 \mathrm{~mm} \mathrm{Hg}$ with adenosine and by $13 \pm 14 \mathrm{~mm} \mathrm{Hg}$ with regadenoson, while diastolic BP decreased by $10 \pm 8 \mathrm{~mm} \mathrm{Hg}$ with both agents. ${ }^{16}$ This drop in BP is attributed to a fall in systemic vascular resistance and usually occurs within 5 minutes of administration of the vasodilator agent. In addition, the heart rate usually increases during the test. In the ADVANCE MPI trial, heart rate increased by $20 \pm 10$ beats/min with adenosine and by $25 \pm 11$ beats/min with regadenoson. This increase in heart rate has been shown to be dissociated from the fall in BP and attributed to direct sympathetic excitation. ${ }^{17}$ Recent literature reviewed by Andrikopoulou and Hage ${ }^{18}$ demonstrates that the heart rate response to vasodilator stress is strongly and independently associated with outcomes whereby a blunted rise in heart rate portends a poor prognosis. Witbrodt et $\mathrm{al}^{8}$ interrogate a multicentre PET registry in order to examine whether the same holds true for BP response.

The study cohort consisted of 3413 patients who underwent Rb-82 PET imaging using adenosine or dipyridamole stress (after excluding 3648 patients who received dobutamine or undocumented stress agent). The BP was measured at baseline and at peak stress (at or around the time of tracer injection) which was approximately around the 7 minutes mark for patients receiving dipyridamole and at the midpoint of the adenosine infusion depending on site-specific protocols. The data had to be pooled together for both stress agents since the stress agent used was not recorded in the registry. As expected, the majority of patients experienced a drop in BP during the test (81\% for systolic and $79 \%$ for diastolic BP). Patients with more intense BP drop tended to be older, and have a higher resting BP. During a median follow-up period of 1.9 years, 270 patients died. On univariate analysis, resting systolic $(P=0.008)$ and diastolic $(P<0.001)$ BPs were significantly associated with mortality, with lower BPs associating with higher risk. The $\mathrm{BP}$ response (stress minus rest) was of borderline significance $(P=0.082)$ with a more intense drop in BP associating with higher risk. After multivariate adjustment for clinical and MPI variables, the association remained statistically significant for resting systolic $(P=0.026)$ and diastolic $(P=$ $0.045) \mathrm{BPs}$ but not for the BP response $(P=0.287)$. The authors concluded that for patients undergoing vasodilator MPI, a lower resting BP is independently associated with mortality on follow-up, while the BP response does not provide incremental prognostic value.

The discrepancy of the prognostic value of the BP response to exercise versus vasodilator stress can be largely attributed to differences in the mechanisms involved in the BP response to these stressors. The BP response to dynamic exercise is determined by cardiac output and therefore by the state of ventricular contractile function; this physiological mechanism underlies the causal relationship between ischemic LV impairment and exertional hypotension. In some patients with ischemic heart disease, an inappropriate decrease in peripheral vascular resistance rather than LV systolic dysfunction has been documented as the dominant mechanism presumably due to activation of ventricular baroreceptors secondary to ischemia. ${ }^{19}$ Importantly, most patients, even those with severe CAD, are not expected to experience myocardial ischemia when undergoing vasodilator MPI. Therefore, both these mechanisms do not apply for vasodilator testing.

With vasodilator stress, several mechanisms may influence the BP response including activation of adenosine receptors in the peripheral vasculature, stimulation of baroreceptors, and modulation of autonomic nerve activity. Both the systolic and diastolic BPs are expected to decrease by $\sim 10 \mathrm{~mm} \mathrm{Hg}$ on average at peak vasodilator stress. ${ }^{20}$ Indeed, in the study of Witbrodt et al, ${ }^{8}$ a small reduction in systolic BP below baseline ( $>-10$ to $\leq 0 \mathrm{~mm} \mathrm{Hg}$ ) was the commonest response to vasodilator stress $(58 \%$ of patients). Larger variations or no changes are also observed, and this should be interpreted in the context of clinical, imaging, and other stress variables. Rarely, vasodilator stress may induce true ischemia in patients with severe obstructive $\mathrm{CAD}$ which can result in a drop of BP secondary to the mechanisms discussed above for exercise-induced hypotension. This rare occurrence is likely to also manifest through other markers of poor prognosis such as high percentage of ischemic myocardium 
on imaging, transient ischemic dilatation, and low poststress ejection fraction. ${ }^{21,22}$ Indeed, these strong predictors of risk may reduce the prognostic power of vasodilatorinduced hypotension on multivariate analysis as suggested by the findings of Witbrodt et $\mathrm{al}^{8}$ Further, since the majority of patients will experience a drop in BP with vasodilator stress due to direct peripheral vasodilation, it becomes difficult if not impossible to distinguish those who experience a drop of $\mathrm{BP}$ due to ischemia from the normal response. In contrast, an abnormal heart rate response to vasodilator stress, i.e., a blunted response, runs directionally opposite to the normal response seen in the majority of patients, a brisk increase in heart rate. This may be the key reason why $\mathrm{BP}$ response does not carry any prognostic information, while the heart rate response to vasodilator stress is a powerful prognostic indicator. ${ }^{18,23,24}$ Finally, the hemodynamic response to vasodilators should not be clinically used to assess whether patients were appropriately 'stressed', since many patients do not have a discernible hemodynamic response to vasodilator administration, ${ }^{8,24}$ and since the effect of vasodilators on coronary blood flow is mediated by mechanisms distinct from those that influence heart rate and BP.

\section{References}

1. Hage FG, Ghimire G, Lester D, McKay J, Bleich S, El-Hajj S, et al. The prognostic value of regadenoson myocardial perfusion imaging. J Nucl Cardiol. 2015;22:1214-21.

2. Farzaneh-Far A, Shaw LK, Dunning A, Oldan JD, O'Connor CM, Borges-Neto S. Comparison of the prognostic value of regadenoson and adenosine myocardial perfusion imaging. J Nucl Cardiol. 2015;22:600-7.

3. Iqbal FM, Hage FG, Ahmed A, Dean PJ, Raslan S, Heo J, et al. Comparison of the prognostic value of normal regadenoson with normal adenosine myocardial perfusion imaging with propensity score matching. JACC Cardiovasc Imaging. 2012;5:1014-21.

4. Doukky R. The prognostic value of regadenoson stress: Has the case been made? J Nucl Cardiol. 2015;22:608-10.

5. Bajaj NS, Singh S, Farag A, El-Hajj S, Heo J, Iskandrian AE, et al. The prognostic value of non-perfusion variables obtained during vasodilator stress myocardial perfusion imaging. J Nucl Cardiol. 2016;23:390-413.

6. Rozanski A, Gransar H, Hayes SW, Friedman JD, Hachamovitch $\mathrm{R}$, Berman DS. Comparison of long-term mortality risk following normal exercise vs adenosine myocardial perfusion SPECT. J Nucl Cardiol. 2010;17:999-1008.

7. Kodama S, Saito K, Tanaka S, Maki M, Yachi Y, Asumi M, et al. Cardiorespiratory fitness as a quantitative predictor of all-cause mortality and cardiovascular events in healthy men and women: A meta-analysis. JAMA. 2009;301:2024-35.

8. Witbrodt B, Goyal A, Kelkar AA, Dorbala S, Chow BJW, Di Carli $\mathrm{MF}$, et al. Prognostic significance of blood pressure response during vasodilator stress $\mathrm{Rb}-82$ positron emission tomography myocardial perfusion imaging. J Nucl Cardiol. 2016. doi: 10.1007/s12350-016-0569-1.

9. Froelicher VF, Quaglietti S. Overview of exercise test interpretation. In: Froelicher VF, Quaglietti S, editors. Handbook of exercise testing. Boston,: Brown Co.; 1996. p. 24-42.
10. Fletcher GF, Ades PA, Kligfield P, Arena R, Balady GJ, Bittner VA, et al. Exercise standards for testing and training: a scientific statement from the American Heart Association. Circulation. 2013;128:873-934.

11. Henzlova MJ, Duvall WL, Einstein AJ, Travin MI, Verberne HJ. ASNC imaging guidelines for SPECT nuclear cardiology procedures: Stress, protocols, and tracers. J Nucl Cardiol. 2016;23:60639.

12. Schultz MG, Otahal P, Cleland VJ, Blizzard L, Marwick TH, Sharman JE. Exercise-induced hypertension, cardiovascular events, and mortality in patients undergoing exercise stress testing: A systematic review and meta-analysis. Am J Hypertens. 2013;26:357-66.

13. Smith RG, Rubin SA, Ellestad MH. Exercise hypertension: An adverse prognosis? J Am Soc Hypertens. 2009;3:366-73.

14. Kwok JM, Christian TF, Miller TD, Hodge DO, Gibbons RJ. Identification of severe coronary artery disease in patients with a single abnormal coronary territory on exercise thallium-201 imaging: The importance of clinical and exercise variables. J Am Coll Cardiol. 2000;35:335-44.

15. O'Neal WT, Qureshi WT, Blaha MJ, Keteyian SJ, Brawner CA, Al-Mallah MH. Systolic blood pressure response during exercise stress testing: The henry ford exercise testing (FIT) Project. J Am Heart Assoc. 2015;4:e002050.

16. Iskandrian AE, Bateman TM, Belardinelli L, Blackburn B, Cerqueira MD, Hendel RC, et al. Adenosine versus regadenoson comparative evaluation in myocardial perfusion imaging: results of the ADVANCE phase 3 multicenter international trial. J Nucl Cardiol. 2007; 14:645-58

17. Hage FG, Heo J, Franks B, Belardinelli L, Blackburn B, Wang W, et al. Differences in heart rate response to adenosine and regadenoson in patients with and without diabetes mellitus. Am Heart J. 2009;157:771-6.

18. Andrikopoulou E, Hage FG. Heart rate response to regadenoson: Making the case for its value in clinical practice. J Nucl Cardiol. 2016;23:575-80

19. Lele SS, Scalia G, Thomson H, Macfarlane D, Wilkinson D, Stafford W, et al. Mechanism of exercise hypotension in patients with ischemic heart disease. Role of neurocardiogenically mediated vasodilation. Circulation. 1994;90:2701-9.

20. Cerqueira MD, Verani MS, Schwaiger M, Heo J, Iskandrian AS. Safety profile of adenosine stress perfusion imaging: Results from the Adenoscan Multicenter Trial Registry. J Am Coll Cardiol. 1994:23:384-9.

21. Emmett L, Ng A, Ha L, Russo R, Mansberg R, Zhao W, et al. Comparative assessment of rest and post-stress left ventricular volumes and left ventricular ejection fraction on gated myocardial perfusion imaging (MPI) and echocardiography in patients with transient ischaemic dilation on adenosine MPI: Myocardial stunning or subendocardial hypoperfusion? J Nucl Cardiol. 2012;19:735-42.

22. Van Tosh A, Votaw JR, Reichek N, Palestro CJ, Nichols KJ. The relationship between ischemia-induced left ventricular dysfunction, coronary flow reserve, and coronary steal on regadenoson stress-gated (82)Rb PET myocardial perfusion imaging. J Nucl Cardiol. 2013;20:1060-8.

23. Bellam N, Veledar E, Dorbala S, Di Carli MF, Shah S, Eapen D, et al. Prognostic significance of impaired chronotropic response to pharmacologic stress Rb-82 PET. J Nucl Cardiol. 2014;21:233-44.

24. Hage FG, Dean P, Iqbal F, Heo J, Iskandrian AE. A blunted heart rate response to regadenoson is an independent prognostic indicator in patients undergoing myocardial perfusion imaging. J Nucl Cardiol. 2011;18:1086-94. 